\section{An unusual duodenal polyp: Brunner's gland hyperplasia}

A 52-year-old man with a 5-day history of black stools (melena) was referred to our digestive endoscopy unit for upper gastrointestinal endoscopy. The patient was not taking aspirin or nonsteroidal anti-inflammatory drugs (NSAIDs) and he had never smoked cigarettes. He did however have non-insulin dependent diabetes and hypertension. On admission, the results of blood analysis showed a normochromic, normocytic anemia with a hemoglobin $(\mathrm{Hb})$ level of $9.3 \mathrm{~g} / \mathrm{dL}$, mean cell volume (MCV) of $89.7 \mathrm{fL}$, and mean cell hemoglobin $(\mathrm{MCH})$ of $30.5 \mathrm{pg}$.

Gastroscopy revealed a pedunculated polyp, approximately $3 \times 1 \mathrm{~cm}$, in the prox- imal duodenum ( $\bullet$ Fig. 1 a,b). The polyp was smooth, with small areas of erosions and some blood spots, but no evidence of active bleeding. The pit pattern was II according to the Kudo classification.

The polyp was completely removed endoscopically using a large-channel gastroscope (GIF-1TQ160; Olympus Medical Systems Corporation, Tokyo, Japan) and a hard straight cap (D-201-12704 with $13.4 \mathrm{~mm}$ outer diameter and $4 \mathrm{~mm}$ length; Olympus Medical Systems Corporation) to obtain better positional control and for a rapid polyp collection after resection. Two hemoclips (EZ-long clip HX-610-090L;
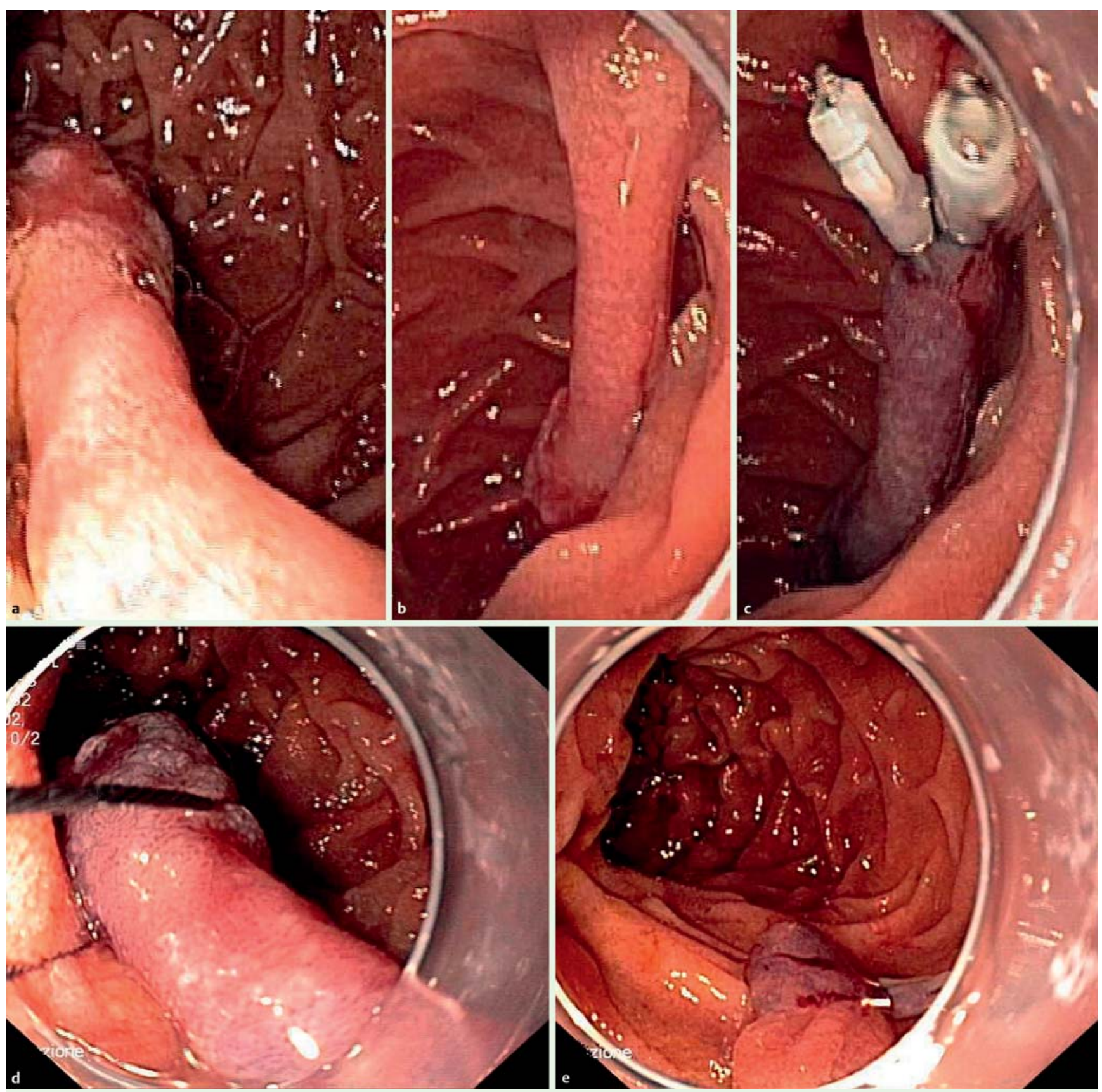

Fig. 1 Endoscopic views showing: a, b a pedunculated polyp, approximately $3 \times 1 \mathrm{~cm}$, in the proximal duodenum; chemoclips applied to the stalk of the polyp; $\mathbf{d}$ the polypectomy being performed with an electrosurgical snare; $\mathbf{e}$ the resection site after polypectomy. 

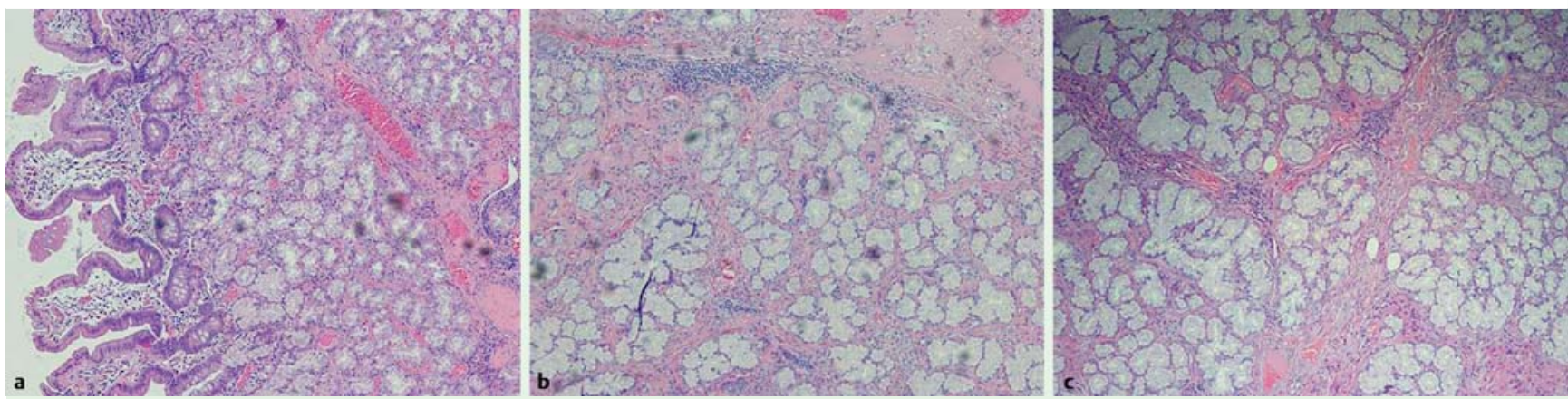

Fig.2 Histopathology of the resected polyp (at increasing levels of magnification) showing proliferation of the Brunner's glands covered by normal duodenal mucosa.

Olympus Medical Systems Corporation) were applied to the stalk before resection to reduce the bleeding risk ( $\bullet$ Fig. 1 c) and the lesion was resected by electrosurgical

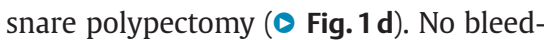
ing or other complications occurred $(\checkmark$ Fig. 1 e) and the polyp was retrieved using a Roth Net device (US Endoscopy, Mentor, Ohio, USA) and cap.

Histological examination of the lesion showed numerous lobules made up of Brunner's glands with normal appearance that were divided by strands of smooth muscle from the muscularis mucosae, focal aggregates of lymphocytes in the stroma, and some cystic dilatations. This was consistent with a diagnosis of Brunner's gland hyperplasia ( $\bullet$ Fig. 2).

Brunner's gland hyperplasia is a rare and benign lesion of the duodenum, which generally has a good prognosis $[1,2]$, although some cases of adenocarcinoma have been described. Its clinical presentation is quite variable, ranging from an asymptomatic condition to abdominal pain, intestinal obstruction, gastrointestinal bleeding, and occasionally the mimicking of a duodenal malignancy $[3,4]$.

In symptomatic patients, surgery has been the main approach for removal in the past, but some cases of endoscopic polypectomy have also been described, with endoscopy representing a more cost-effective and less invasive approach [5]. Our case is an example of symptomatic Brunner's gland hyperplasia successfully treated by endoscopic resection without any complications.

Endoscopy_UCTN_Code_TTT_1AO_2AG

Competing interests: None

\section{Lucia Sparano ${ }^{1}$, Pietro Cesari ${ }^{1}$, Mauro Lovera ${ }^{1}$, Fausto Zorzi ${ }^{2}$, Alessandro Paterlini ${ }^{1}$}

${ }^{1}$ Gastroenterology and Endoscopy Department, Fondazione Poliambulanza Hospital, Brescia, Italy

2 Histopathology Department, Fondazione Poliambulanza Hospital, Brescia, Italy

\section{References}

1 Franzin G, Musola R, Ghidini $O$ et al. Nodular hyperplasia of Brunner's glands. Gastrointest Endosc 1985; 31: $374-378$

2 HolJW, Stuifbergen WN, Teepen JL et al. Giant Brunner's hamartomas of the duodenum and obstructive jaundice. An overview of the literature and suspicion of malignancy in a case. Dig Surg 2007; 24: 452-455
3 Krishnamurthy P, Junaid $O$, Moezzi $J$ et al Gastric outlet obstruction caused by Brunner's gland hyperplasia: case report and review of literature. Gastrointest Endosc 2006; 64: 464-467

4 Mayoral W, Salcedo JA, Montgomery E et al. Biliary obstruction and pancreatitis caused by Brunner's gland hyperplasia of the ampulla of Vater: a case report and review of the literature. Endoscopy 2000; 32: 998 1001

5 Hizawa K, Iwai K, Esaki $M$ et al. Endosonographic features of Brunner's glands hamartomas which were subsequently resected endoscopically. Endoscopy 2002; 34: $956-$ 958

Bibliography

Dol http://dx.doi.org/

10.1055/s-0034-1377207

Endoscopy 2014; 46: E310-E311

(c) Georg Thieme Verlag KG

Stuttgart · New York

ISSN 0013-726X

\section{Corresponding author}

\section{Lucia Sparano, MD}

Gastroenterology and Endoscopy Department

Via Bissolati 57

25124 Brescia

Italy

Fax: +39-30-3515339

lucia.sparano@poliambulanza.it 